\title{
Adaptive servoventilation improves cardiac function and respiratory stability
}

\author{
Olaf Oldenburg - Thomas Bitter • Roman Lehmann - Stefan Korte • \\ Zisis Dimitriadis · Lothar Faber · Anke Schmidt • Nina Westerheide • \\ Dieter Horstkotte
}

Received: 26 March 2010/ Accepted: 25 August 2010/Published online: 12 September 2010

(c) Springer-Verlag 2010

\begin{abstract}
Cheyne-Stokes respiration (CSR) in patients with chronic heart failure (CHF) is of major prognostic impact and expresses respiratory instability. Other parameters are daytime $\mathrm{pCO}_{2}, \mathrm{VE} / \mathrm{VCO}_{2}$-slope during exercise, exertional oscillatory ventilation (EOV), and increased sensitivity of central $\mathrm{CO}_{2}$ receptors. Adaptive servoventilation (ASV) was introduced to specifically treat CSR in CHF. Aim of this study was to investigate ASV effects on CSR, cardiac function, and respiratory stability. A total of 105 patients with CHF (NYHA $\geq$ II, left ventricular ejection fraction $(\mathrm{EF}) \leq 40 \%$ ) and CSR (apnoea-hypopnoea index $\geq 15 / \mathrm{h}$ ) met inclusion criteria. According to adherence to ASV treatment (follow-up of $6.7 \pm 3.2$ months) this group was divided into controls (rejection of ASV treatment or usage $<50 \%$ of nights possible and/or $<4 \mathrm{~h} /$ night; $n=59)$ and ASV ( $n=56)$ adhered patients. In the ASV group, ventilator therapy was able to effectively treat CSR. In contrast to controls, NYHA class, EF, oxygen uptake, 6-min walking distance, and NT-proBNP improved significantly. Moreover, exclusively in these patients $\mathrm{pCO}_{2}$, $\mathrm{VE} / \mathrm{VCO}_{2}$-slope during exercise, $\mathrm{EOV}$, and central $\mathrm{CO}_{2}$
\end{abstract}

O. Oldenburg $(\varangle) \cdot$ T. Bitter · Z. Dimitriadis · L. Faber ·

D. Horstkotte

Department of Cardiology, Heart and Diabetes Centre North Rhine Westphalia, University Hospital, Ruhr University Bochum, Georgstrasse 11, 32545 Bad Oeynhausen, Germany e-mail: akleemeyer@hdz-nrw.de

R. Lehmann · S. Korte · A. Schmidt

Cardiac Research Unit, Heart and Diabetes Centre

North Rhine Westphalia, Ruhr University Bochum,

Bad Oeynhausen, Germany

N. Westerheide

Department of Business Administration and Economics,

University of Bielefeld, Bielefeld, Germany receptor sensitivity improved. In CHF patients with CSR, ASV might be able to improve parameters of SDB, cardiac function, and respiratory stability.

Keywords Chronic heart failure - Cheyne-Stokes respiration - Sleep-disordered breathing - Adaptive servoventilation · Respiratory instability $\cdot$ Cardiac function

\section{Introduction}

Sleep-disordered breathing (SBD) is common in patients with chronic heart failure (CHF) [1,2]. The presence of obstructive (OSA) as well as central sleep apnoea (CSA) with Cheyne-Stokes respiration (CSR) has been shown to be of major prognostic impact in these patients [3-5]. Whereas OSA seems to be a risk factor for occurrence and worsening of heart failure per se, CSR seems to mirror cardiac function and worsens prognosis with increasing severity [6-9].

In heart failure, nocturnal CSR might only be one expression of an unstable respiratory control. There is no generally accepted definition of "respiratory instability" in these patients, but markers of an unstable respiratory control (respiratory instability) have been identified and their prognostic relevance in heart failure has been proved [10-14]. A key pathophysiologic element is the stimulation of vagal irritant receptors by elevated left ventricular filling pressures and consecutive increase in pulmonary artery pressure $[6,8]$. This contributes to an augmented $\mathrm{CO}_{2^{-}}$ chemosensitivity [10-14] resulting in chronic hyperventilation with hypocapnia [13, 14], enhanced ventilatory response to exercise with inefficient ventilation (VE/ $\mathrm{VCO}_{2}$-slope), and exertional oscillatory ventilation (EOV) [15]. 
Adaptive servoventilation (ASV) was recently introduced to specifically treat CSR in heart failure patients [16]. ASV uses low levels of end-expiratory positive airway pressure (EPAP) to which a variable amount of inspiratory pressure support (IPAP) is added. In parallel to decreasing breathing efforts during decrescendo phase of Cheyne-Stokes respiration, ventilatory support (IPAP) is increased and when effort increases, ventilatory support is reduced again. However, because CSR in CHF patients is characterised by chronic hyperventilation, the ASV algorithm used in the present study is designed to reduce hyperventilation by targeting minute ventilation that is $90 \%$ of the average over the previous few minutes [16]. Previous studies demonstrated beneficial effects on parameters of SDB, quality of life, and cardiac function [16-23]. However, to our knowledge, no study exists to analyse the effects on parameters of respiratory stability as a possible underlying mechanism of CSR in CHF.

Aim of this study was thus to investigate the long-term effects of ASV on parameters of SDB, cardiac function, and respiratory stability in CHF patients with CSR.

\section{Materials and methods}

\section{Patients}

This study included patients with stable CHF (NYHA class $\geq \mathrm{II}$; $\mathrm{EF} \leq 40 \%$; first $\mathrm{CHF}$ diagnosis at least 6 months prior to enrolment), treated according to current guidelines ( $\geq 3$ months) and moderate to severe SDB $(\mathrm{AHI} \geq 15 / \mathrm{h})$ with the vast majority $(>80 \%)$ of events being central (Cheyne-Stokes or periodic breathing). Patients with pacemakers, defibrillators, or resynchronization devices were included, at least 6 months after implantation. Exclusion criteria were prediagnosed or pretreated SDB, decompensated heart failure, chronic obstructive lung disease $\left(\mathrm{FEV}_{1} / \mathrm{VC}<70 \%\right)$, history of stroke, neuropathy, or myocardial infarction within the last 3 months. The study was approved by the local ethical committee. All patients were informed individually and gave written informed consent.

\section{Sleep studies}

Sleep studies were performed by either in-hospital unattended cardiorespiratory polygraphy as described before [1] or attended polysomnography (N 7000 or S7000, Embla, The Netherlands). Analyses were performed by Somnologica software (Embla, The Netherlands), reviewed and corrected by two independent SDB specialists, not involved in the further treatment of these patients. Hypopnoea was defined as a $\geq 30 \%$ reduction in airflow in combination with a drop in oxygen saturation of $\geq 3 \%$. Apnoea was defined as a cessation in airflow for $\geq 10 \mathrm{~s}$, in case of CSA without any abdominal or thoracic breathing efforts and in case of OSA with typical efforts. To be classified as CSR, more than $80 \%$ of all respiratory events (hypopnoeas or apnoeas) had to be central with either typical CSR (crescendo-decrescendo ventilation with interposed central apnoea) or periodic breathing (crescendo-decrescendo ventilation with interposed hypopnoea). The apnoea-hypopnoea index (AHI) describes the number of apnoea and hypopnoea episodes per hour sleeping time. We considered an AHI $\geq 15 / \mathrm{h}$ to indicate moderate to severe SDB. In addition, cardiorespiratory polygraphy or polysomnography on therapy was performed at each follow-up visit to document therapeutic efficacy.

\section{ASV therapy}

Sleep study results and the rationale for ASV therapy were discussed with each patient individually. Therapy was initiated using the AutoSet ${ }^{\mathrm{TM}} \mathrm{CS} 2$ device and full face masks (Ultra Mirage ${ }^{\mathrm{TM}}$; ResMed, Germany). The aim was to reduce the AHI to $\leq 10 / \mathrm{h}$ before discharge from hospital using a minimum of positive airway pressure support. The usual settings used on the first night of treatment were expiratory positive airway pressure (EPAP) $4-5 \mathrm{cmH}_{2} \mathrm{O}$, inspiratory positive airway pressure (IPAP) - minimum $3 \mathrm{cmH}_{2} \mathrm{O}$, maximum $8-10 \mathrm{cmH}_{2} \mathrm{O}$. Heart rate and blood pressure were monitored continuously for at least $20 \mathrm{~min}$ during therapy initiation.

\section{Compliance and efficacy data}

The AutoSet ${ }^{\mathrm{TM}} \mathrm{CS} 2$ device stores compliance and efficacy data, which were downloaded and analysed using ResScan ${ }^{\mathrm{TM}}$ software (ResMed, Germany) at follow-up visits. The data recorded include days, hours, and minutes the device was used, AHI, and apnoea index (AI).

Definition of compliance, ASV-group and controls

Sleep study results were discussed with every patient individually. Because this study was not intended to be randomized, immediate initiation of ASV treatment was not possible in some cases (Fig. 1). In some cases patients denied a prolongation of their hospital stay or logistic reasons let to a premature discharge. However, most of the patients agreed to test ASV therapy. During mask fitting and/or daytime testing of ASV treatment some rejected further treatment and were resigned to the control group. Patients in whom ASV therapy were initiated and AutoSet ${ }^{\mathrm{TM}}$ CS device was prescribed, regular follow-up visits 


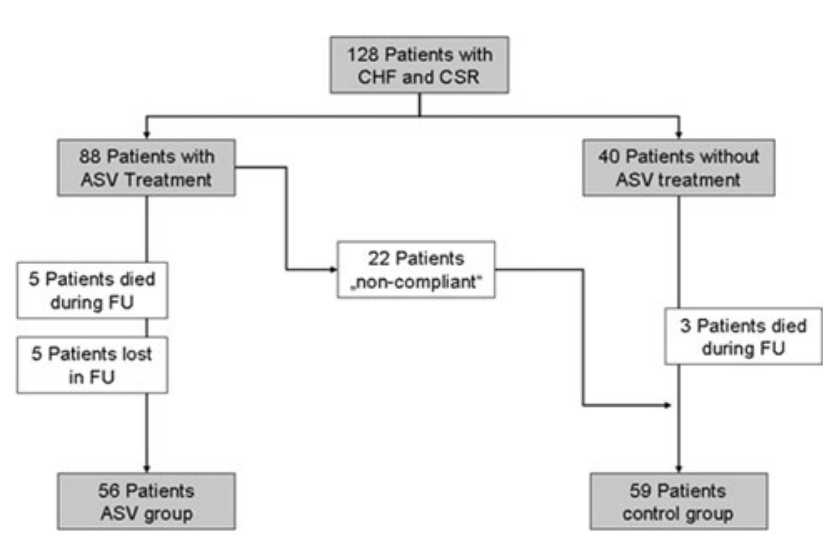

Fig. 1 Flow-chart of study population

were scheduled. According to the widely accepted definition of compliance and adherence in most CPAP trials, non-compliance was defined as a device usage $\leq 50 \%$ of possible nights and/or a use $\leq 4 \mathrm{~h}$ per night. According to this definition, non-compliant ASV patients, the ones in whom therapy was not initiated and those who rejected further treatment after mask fitting or ASV testing period, were resigned to the control group. Because most of these controls are seen on a regular basis, e.g. while checking their pacemakers, ICDs, or CRT devices, a routine followup was possible even in these patients.

\section{Echocardiography}

Two-dimensional echocardiography was performed to evaluate LV function in all patients. EF was determined using apical 4- and 2-chamber views and the modified Simpson method. LAD and LVEDD were measured at parasternal long axis from M-mode recordings. All recordings were performed on GE ultrasound systems (Vivid 7 Dimension) and analysed in a blinded way by one experienced echocardiographer (L.F.).

\section{Cardiopulmonary exercise testing}

Symptom-limited bicycle exercise testing with spirometry (CPX) was used to evaluate exercise tolerance, oxygen consumption at the individual aerobic-anaerobic threshold $\left(\mathrm{VO}_{2}-\mathrm{AT}\right)$, peak oxygen consumption $\left(\mathrm{VO}_{2}\right.$ peak), and $\mathrm{VE} /$ $\mathrm{VCO}_{2}$-slope (ZAN Ferraris, Germany). Exercise testing started with $10 \mathrm{~W}$ of workload with a continuous increase of $10 \mathrm{~W} / \mathrm{min}$. Maximum workload and total exercise time were recorded; predicted $\mathrm{VO}_{2}$-peak was calculated automatically taking gender and age into account. Determination of EOV at rest and during exercise was done in a blinded fashion by an independent specialist (Z.D.) according to Corra et al. [13].
6-Min walking distance

A standardised hallway 6-min walk test was performed as recommended by the American Thoracic Society [24].

Blood samples

Blood samples for determination of natriuretic peptides (NT-proBNP) as well as full blood counts and clinical chemistry were drawn in the setting of determination of patient's history and physical examination.

Blood gas analysis

Capillary blood gas samples were taken during the day (2:00 pm to 4:00 pm) from a hyperaemic ear lobe while patients were sitting in a chair for at least $5 \mathrm{~min}$.

Lung function and rebreathing test

Body plethysmography including determination of CO diffusion capacity by single-breath method was performed according to current ATS/ERS guidelines (ZAN, Germany). Measurements of hyperoxic-hypercapnic ventilatory response (HCVR; ZAN, Germany) were performed as described by Javaheri [11]. HCVR was determined using Read's rebreathing method [25] starting with a mixture of $\mathrm{CO}_{2}(7 \%)$ and $\mathrm{O}_{2}(93 \%)$ and linear slope regression analysis.

\section{Statistics}

Continuous data are expressed as mean \pm SD. Statistical analyses were performed using SigmaPlot for Windows ${ }^{\mathrm{TM}}$ (Version 11.0, Systat Software Ltd.). Changes within a group were analysed by Wilcoxon signed rank test and differences between the ASV and control group by MannWhitney $U$ test. Chi-square or binomial proportions tests were used to calculate proportions. $P<0.05$ was considered significant for all comparisons.

\section{Results}

Patient characteristics

Demographic and clinical characteristics of patients are summarised in Table 1. Groups did not differ with respect to age, BMI, aetiology of heart failure, heart rhythm, medication, NYHA class, nocturia, echocardiographic parameters (including EF), oxygen uptake during CPX, 6-min walking distance, parameters of sleep-disordered breathing, NT-proBNP concentrations, and other laboratory 
Table 1 Demographic and clinical characteristics of patients included into the ASV or control group

\begin{tabular}{lll}
\hline & ASV & Controls \\
\hline Number, $n$ & 56 & 59 \\
Follow-up period (months) & $6.7 \pm 3.2$ & $6.2 \pm 3.1$ \\
Age (years) & $67.7 \pm 9.5$ & $62.5 \pm 11.8$ \\
Gender, males & $54(96.4 \%)$ & $52(88.1 \%)^{*}$ \\
BMI $\left(\mathrm{kg} / \mathrm{m}^{2}\right)$ & $28.8 \pm 4.8$ & $27.3 \pm 4.0$ \\
Ischemic heart disease, $n$ & $35(62.5 \%)$ & $41(60.5 \%)$ \\
Rhythm & & \\
Sinusrhythm, $n$ & $35(62.5 \%)$ & $35(59.3 \%)$ \\
Atrial fibrillation, $n$ & $10(17.9 \%)$ & $12(20.3 \%)$ \\
Pacemaker, $n$ & $9(16.1 \%)$ & $12(20.3 \%)$ \\
Medication & & \\
ACE-inhibitors, ARB & $56(100 \%)$ & $57(96.6 \%)$ \\
$\beta$-Blocker & $54(96.4 \%)$ & $56(94.9 \%)$ \\
Diuretics & $45(80.4 \%)$ & $54(91.5 \%)$ \\
Aldosterone-RB & $32(57.1 \%)$ & $41(69.5 \%)$ \\
Digitalis & $20(35.7 \%)$ & $23(39.0 \%)$ \\
\hline
\end{tabular}

$A R B$ angiotensin receptor blocker, Aldosterone-RB aldosteronereceptor blocker

$* p<0.05$, ASV versus control group

parameters. The only differences seen in baseline conditions were with respect to gender and $\mathrm{pCO}_{2}$. A statistically higher proportion of males and lower baseline values for $\mathrm{pCO}_{2}$ were documented in the ASV group.

\section{NYHA class and nocturia}

NYHA class improved in ASV-treated patients from $2.6 \pm 0.6$ to $1.9 \pm 0.7(p<0.001)$ with no change in the control group ( $2.5 \pm 0.5$ to $2.3 \pm 0.8, p=$ n.s.). In parallel, frequency of nocturia significantly decreased with ASV treatment $(1.6 \pm 1.3 /$ night to $1.1 \pm 1.0 /$ night, $p=0.006)$ with no significant change in controls $(1.6 \pm 1.1 /$ night to $1.4 \pm 1.5 /$ night $)$.

\section{Echocardiography}

In ASV-treated patients an absolute increase in EF of $+4.04 \pm 8.0 \%(29.9 \pm 6.1$ to $34.0 \pm 8.8 \%, p=0.003)$ was documented. This represents a relative increase of $+16.6 \pm 35.5 \%$. In controls, there were no change in $\mathrm{EF}$ $(+0.26 \pm 6.0 \%, 27.8 \pm 7.4$ vs. $28.1 \pm 8.7 \%, p=$ n.s. $)$, which represents a non-significant relative change of $+2.3 \pm 22.7 \%$ (Fig. 2). LVEDD decreased in the ASV group by $-3.8 \pm 13.3 \%(67.2 \pm 8.5$ to $64.5 \pm 11.0 \mathrm{~mm}$, $p=0.007)$, but remained unchanged in controls $(+2.2 \pm$ $9.0 \%, 69.8 \pm 11.3$ to $71.5 \pm 12.3 \mathrm{~mm}, p=$ n.s.). There was no significant change in left atrial size in ASV-treated
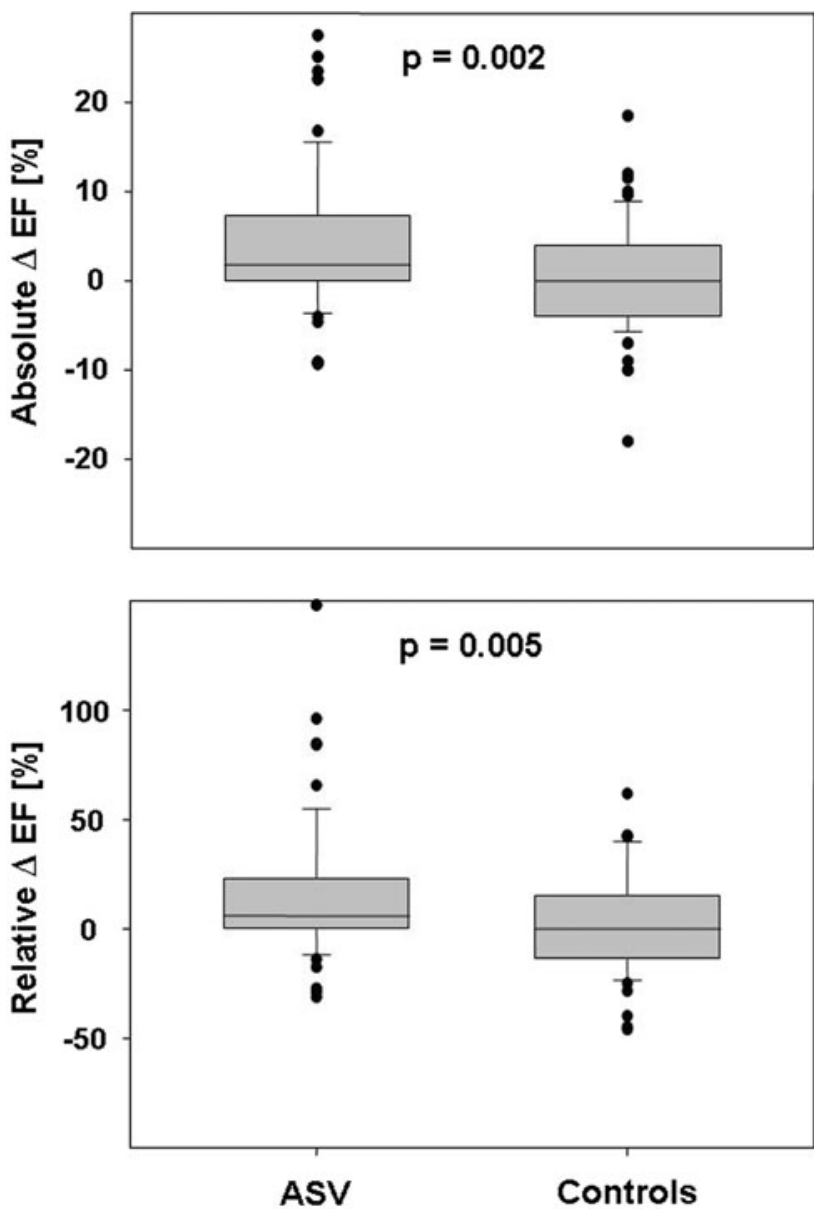

Fig. 2 Changes in left ventricular ejection fraction (EF) from baseline to follow-up in ASV-treated patients and controls. Top absolute differences (follow-up EF-baseline EF); bottom relative changes compared to baseline $\mathrm{EF}$

patients $(+1.8 \pm 16.2 \%, 49.5 \pm 8.5$ to $49.8 \pm 8.5 \mathrm{~mm}$, $p=$ n.s. $)$, but there was a significant increase $(+5.7 \pm$ $14.4 \%, \quad 50.3 \pm 9.4$ to $53.0 \pm 8.2 \mathrm{~mm}, p=0.01)$ in controls.

\section{Cardiopulmonary exercise}

In ASV-treated patients workload $(88.4 \pm 32$ to $104.0 \pm 37 \mathrm{~W}, \quad p<0.001), \quad \mathrm{VO}_{2}$-AT $\quad(12.9 \pm 3.7$ to $14.9 \pm 4.4 \mathrm{ml} / \mathrm{kg} / \mathrm{min}, p=0.02)$, peak $\mathrm{VO}_{2}(15.4 \pm 4.5$ to $17.3 \pm 4.7 \mathrm{ml} / \mathrm{kg} / \mathrm{min}, p=0.004)$, and predicted $\mathrm{VO}_{2}$ peak $(63.7 \pm 19.5$ to $73.5 \pm 19.8 \%, p<0.001)$ increased. In parallel, $\mathrm{VE} / \mathrm{VCO}_{2}$-slope decreased $(35.1 \pm 6.3$ to $33.1 \pm 5.9, p=0.02$, Fig. 3). Within the control group workload $(86.9 \pm 32$ vs. $82.5 \pm 32 \mathrm{~W}, p=$ n.s. $), \mathrm{VO}_{2}$-AT $\left(13.7 \pm 4.1\right.$ to $13.0 \pm 3.9 \mathrm{ml} / \mathrm{kg} / \mathrm{min}, p=$ n.s.), peak $\mathrm{VO}_{2}$ $(15.4 \pm 5.1$ to $14.7 \pm 5.1 \mathrm{ml} / \mathrm{kg} / \mathrm{min}, p=$ n.s. $)$, predicted $\mathrm{VO}_{2}$ peak $(61.5 \pm 14.9$ to $60.2 \pm 18.3 \%, p=$ n.s. $)$, and $\mathrm{VE} / \mathrm{VCO}_{2}$-slope $(34.3 \pm 6.2$ to $36.1 \pm 8.9, p=$ n.s. $) \mathrm{did}$ not change. There was a significant difference in the 

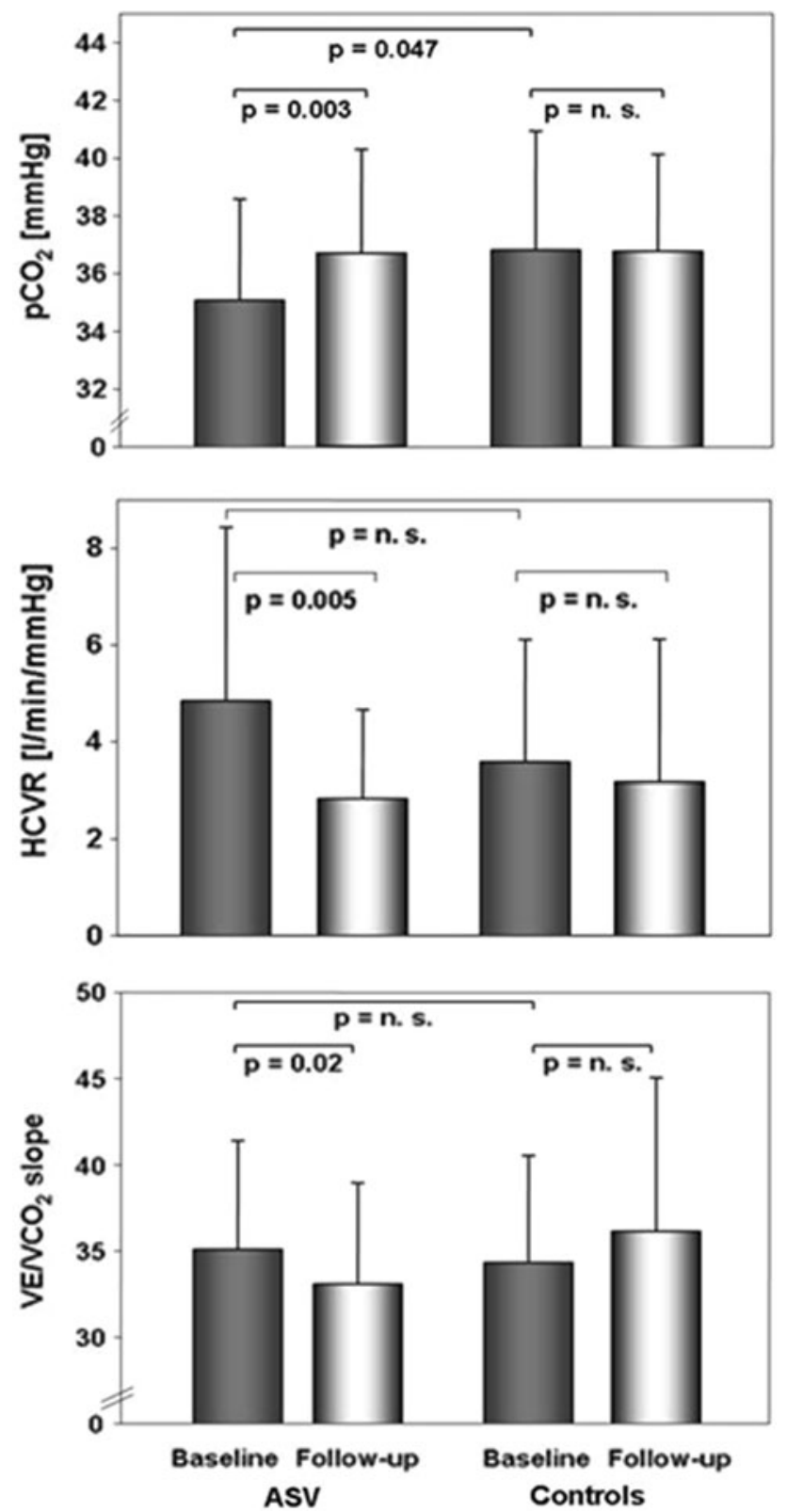

Fig. 3 Changes in parameters of respiratory stability. Top daytime capillary $\mathrm{pCO}_{2}$; middle changes in central $\mathrm{CO}_{2}$-receptor sensitivity as measured by hyperoxic-hypercapnic ventilatory response (HCVR); bottom changes in $\mathrm{VE} / \mathrm{VCO}_{2}$-slope during cardiopulmonary exercise testing presence of resting and exercise EOV (Table 2). In ASVtreated patients EOV was more at rest, but improved during therapy, whereas in controls, EOV deteriorated during the follow-up period.

\section{6-Min walking test}

Walking distance in ASV-treated patients increased from $393 \pm 96$ to $423 \pm 98 \mathrm{~m}(p=0.03)$ and remained unchanged within the control group, $384 \pm 123$ to $391 \pm 113 \mathrm{~m}(p=$ n.s. $)$.

\section{Laboratory parameters}

In ASV-treated patients, NT-proBNP decreased significantly from $2,582 \pm 3,822$ to $1,191 \pm 1,018 \mathrm{pg} / \mathrm{ml}$ $(p=0.001)$. In controls, there was no significant change in NT-proBNP serum levels $(2,081 \pm 2,365$ to $2,729 \pm$ $5,363 \mathrm{pg} / \mathrm{ml}, p=$ n.s.). Haemoglobin concentration did not change significantly in either group (ASV: $14.1 \pm 1.3$ vs. $13.9 \pm 1.2 \mathrm{~g} / \mathrm{dl}$; controls: $14.0 \pm 1.4 \mathrm{vs} .13 .8 \pm 1.4 \mathrm{~g} / \mathrm{dl})$. Sodium concentration decreased in controls (139.6 \pm 2.8 to $138.2 \pm 3.2 \mathrm{mmol} / \mathrm{l}, p=0.004)$, but not in the ASV group (139.9 \pm 3.3 vs. $139.9 \pm 2.8 \mathrm{mmol} / \mathrm{l}, \quad p=$ n.s. $)$. Creatinine concentration increased exclusively in controls $(1.33 \pm 0.4$ to $1.40 \pm 0.5 \mathrm{mg} / \mathrm{dl}, p=0.03)$, but remained unchanged in ASV patients (1.33 \pm 0.4 vs. $1.35 \pm 0.4 \mathrm{mg} /$ $\mathrm{dl}, p=$ n.s.).

\section{Blood gas analysis}

There were no changes in blood gas parameters in the control group: $\mathrm{pH} 7.44 \pm 0.04$ vs. $7.43 \pm 0.04, \mathrm{pCO}_{2}$ $36.77 \pm 4.06$ vs. $36.77 \pm 3.36 \mathrm{mmHg}, \mathrm{pO}_{2} 77.75 \pm 11.22$ vs. $79.53 \pm 12.28 \mathrm{mmHg}, \mathrm{SaO}_{2} 96.07 \pm 2.04$ vs. $93.06 \pm$ $16.43 \%$ ( $p=$ n.s. each). In ASV patients $\mathrm{pH}$ decreased from $7.44 \pm 0.03$ to $7.43 \pm 0.03(p=0.02)$ and $\mathrm{pCO}_{2}$, which was slightly lower at baseline compared to controls $(p=0.047)$, increased from $35.1 \pm 3.5$ to $36.7 \pm$ $3.6 \mathrm{mmHg}$ ( $p=0.003$, Fig. 3). $\mathrm{SaO}_{2}(95.8 \pm 3.5$ vs. $96.4 \pm 2.2 \%, p=$ n.s. $)$ and $\mathrm{pO}_{2}(76.6 \pm 11.5$ vs. $80.2 \pm$ $9.3 \mathrm{mmHg}, p=$ n.s.) did not change in the ASV group.

Table 2 Exertional oscillatory ventilation (EOV) at rest and during exercise in ASV treated patients versus controls

\begin{tabular}{lllll}
\hline & ASV & & \multicolumn{2}{l}{ Controls } \\
\cline { 2 - 3 } \cline { 5 - 6 } & Baseline (\%) & Follow-up (\%) & Baseline (\%) & Follow-up (\%) \\
\hline Resting EOV & $46.8^{\#}$ & 31.9 & $22.9^{\#}$ & $45.8^{*}$ \\
Exercise EOV & 55.3 & $21.3^{*}$ & 35.4 & 54.2 \\
\hline
\end{tabular}

$* p<0.05$ within group comparison baseline versus follow-up

\# $p<0.05$ ASV baseline versus control baseline 


\section{HCVR and pulmonary function}

Baseline HCVR was not significantly different between the ASV group and controls (Fig. 3). A significant decrease was observed in ASV-treated patients only (4.84 \pm 3.59 to $2.83 \pm 1.83 \mathrm{l} / \mathrm{min} / \mathrm{mmHg}, p=0.005$ vs. $3.58 \pm 2.54$ to $3.17 \pm 2.95 \mathrm{l} / \mathrm{min} / \mathrm{mmHg}, \quad p=$ n.s.). Major results of pulmonary function analyses are summarised in Table 3.

\section{Parameters of sleep-disordered breathing}

Parameters of SDB did not differ at baseline, but every parameter obtained improved during ASV treatment (Table 4). Analysis of device stored data documented a usage of $87 \pm 15 \%$ of nights possible (median $82 \%$ ) or $6: 44 \pm 1: 07$ (h:min) per night (median 6:45 h:min).

Table 3 Pulmonary function in ASV and controls

\begin{tabular}{llllll}
\hline & ASV & & \multicolumn{2}{l}{ Controls } \\
\cline { 2 - 3 } \cline { 5 - 6 } & Baseline & Follow-up & & Baseline & Follow-up \\
\hline IVC $(\%)$ & $81.8 \pm 15.6$ & $82.4 \pm 13.8$ & & $83.4 \pm 13.0$ & $81.2 \pm 17.8$ \\
FEV1 $(\%)$ & $78.1 \pm 15.4$ & $83.4 \pm 16.0$ & $77.9 \pm 15.0$ & $76.1 \pm 18.5$ \\
$\begin{array}{l}\text { FEV1/IVC } \\
(\%)\end{array}$ & $95.2 \pm 12.5$ & $99.6 \pm 9.5$ & & $91.5 \pm 9.2$ & $94.1 \pm 14.3$ \\
KCO $(\%)$ & $94.4 \pm 21.1$ & $93.6 \pm 28.5$ & & $88.4 \pm 22.0$ & $85.1 \pm 18.1$ \\
\hline
\end{tabular}

There were no significant differences

$I V C$ inspiratory vital capacity, FEVI forced expiratory volume within $1 \mathrm{~s}, K C O$ pulmonary gas transfer coefficient for carbon monoxide, corrected for patient's haemoglobin value and alveolar volume

Table 4 Sleep-disordered breathing parameters obtained by cardiorespiratory polygraphy or polysomnography in ASV-treated patients and controls

\begin{tabular}{lccc}
\hline & \multicolumn{2}{l}{ ASV } & \multirow{2}{*}{$\begin{array}{l}\text { Controls } \\
\text { Baseline }\end{array}$} \\
\cline { 2 - 3 } & Baseline & Follow-up & Bas \\
\hline $\mathrm{AHI}\left(\mathrm{h}^{-1}\right)$ & $39.7 \pm 17.8$ & $6.1 \pm 12.1^{*}$ & $36.6 \pm 13.2$ \\
$\mathrm{AI}\left(\mathrm{h}^{-1}\right)$ & $24.0 \pm 16.4$ & $2.6 \pm 10.5^{*}$ & $21.2 \pm 13.2$ \\
$\mathrm{OAI}\left(\mathrm{h}^{-1}\right)$ & $2.7 \pm 5.6$ & $1.9 \pm 9.8$ & $2.0 \pm 6.7$ \\
$\mathrm{CAI}\left(\mathrm{h}^{-1}\right)$ & $17.2 \pm 16.0$ & $0.4 \pm 1.1^{*}$ & $17.8 \pm 14.0$ \\
$\mathrm{MAI}\left(\mathrm{h}^{-1}\right)$ & $3.8 \pm 9.2$ & $0.3 \pm 0.8^{*}$ & $2.3 \pm 3.6$ \\
$\mathrm{HI}\left(\mathrm{h}^{-1}\right)$ & $16.1 \pm 10.6$ & $5.1 \pm 12.4^{*}$ & $15.6 \pm 10.4$ \\
Mean SaO & $92.8 \pm 2.0$ & $94.2 \pm 1.8^{*}$ & $92.8 \pm 2.0$ \\
Min. SaO $\mathrm{SaO}_{2}(\%)$ & $81.6 \pm 5.8$ & $87.1 \pm 4.7^{*}$ & $81.5 \pm 5.8$ \\
Mean desaturation $(\%)$ & $6.7 \pm 3.0$ & $4.8 \pm 2.0^{*}$ & $8.2 \pm 11.6$ \\
\hline
\end{tabular}

There were no baseline differences between ASV and controls; with ASV all parameters improved significantly $(* p<0.01)$

$A H I$ apnoea-hypopnoea index, $A I$ apnoea index, $o A I$ obstructive apnoea index, $c A I$ central apnoea index, $m A I$ mixed apnoea index, $H I$ hypopnoea index, $\mathrm{SaO}_{2}$ oxygen saturation measured by pulse oximetry
Automatic analysis documented a mean AHI of $3.3 \pm 2.5 / \mathrm{h}$ and an $\mathrm{AI}$ of $0 \pm 0.7 / \mathrm{h}$ during the entire follow-up period.

\section{Discussion}

In this study, we showed that in heart failure patients with CSR, ASV is able to reduce nocturnal respiratory events, improve cardiac function and respiratory stability. In patients compliant to ASV, apnoea and hypopnoea events were reduced to normal values, NYHA functional class improved, and nocturia frequency was reduced. In contrast to controls EF, walking distance and exercise capacity increased, while parameters of respiratory instability improved remarkably: daytime hyperventilation was reduced, sensitivity of central $\mathrm{CO}_{2}$ receptors decreased, while exercise ventilation got more efficient and EOV at rest and during exercise lessened.

There are several studies demonstrating the superiority of ASV in the treatment of CSR. Teschler et al. [16] first compared the efficacy of ASV treatment of Cheyne-Stokes respiration in heart failure patients. In an overnight study, ASV was most efficient to improve CSR compared to oxygen, continuous positive airway pressure (CPAP) or bilevel positive airway pressure (BiPAP) ventilation. In a retrospective analysis of a non-selected cohort of 100 patients, in whom 32 patients had heart failure, Allam et al. [17] compared the efficacy of ASV on central sleep apnoea, Cheyne-Stokes respiration, and complex sleep apnoea (compSAS) in patients whose sleep-related breathing problems were not easily controlled with continuous positive airway pressure (CPAP) ventilation. In their overnight study, ASV resulted in substantial improvement in sleep-disordered breathing as well as in sleep architecture and symptoms, which was superior to CPAP or bilevel positive airway (BiPAP) treatment.

The present investigation goes far beyond these previous studies. It describes the long-term effects of ASV on symptoms, sleep-disordered breathing parameters, cardiopulmonary function, and respiratory control stability in patients with heart failure and reduced ejection fraction. This study confirms previous studies demonstrating a remarkable long-term effect of ASV on CSR parameters [18-20]. Peperell reported a sustained decrease in AHI after 1 month $(24.7 \pm 11.3 / \mathrm{h}$ to $5.0 \pm 1.4 / \mathrm{h}, p<0.001)$ and Töpfer a decrease from $48.2 \pm 11.6 / \mathrm{h}$ to $6.4 \pm 8.3 / \mathrm{h}$ after 6 weeks of ASV treatment $(p<0.001)$ [18, 19]. Philippe et al. [20] compared the effectiveness and compliance of ASV and CPAP in heart failure patients with CSR. In this study, only ASV was able to decrease the AHI below 10/h in every patient after 3 and 6 months. Schädlich et al. [21], performing one of the first long-term studies on ASV in these patients, demonstrated a sustained beneficial 
effect of ASV on several parameters, including AHI after 3 and 12 months of treatment. In the present study, AHI decreased from $39.7 \pm 17.8 / \mathrm{h}$ to $6.1 \pm 12.1 / \mathrm{h}(p<0.001)$ after slightly more than 6 months of treatment, which is in close agreement with the above-mentioned studies and our previous results [22].

In a previous pilot study, we demonstrated favourable effects of ASV on cardiac function [22]. As before, this study was able to demonstrate significant improvements concerning heart failure symptoms (NYHA-class, nocturia), echocardiographic parameters (EF, LVEDD), exercise capacity $\left(\mathrm{VO}_{2}\right.$, walking distance), and humoral parameters (NT-proBNP). These effects were not seen in controls. In contrast, prognostically relevant parameters deteriorated in controls: renal function declined slightly (creatinine) and sodium concentration decreased as well. Changes in $\mathrm{EF}(+4.04 \pm 8 \%)$ presented here are significant and clinically relevant, but lower than documented before [20-23]. However, even an absolute increase in EF of $4 \%$ is comparable to the effect of modern drug or resynchronization therapy; an increase of $5 \%$ in EF was documented with metoprolol after 10 months, and in the MIRACLE-ICD trail an increase of $4.1 \%$ was seen using CRT [26, 27]. Thus, an increase of $4 \%$ seen in our patients seems to be promising, especially taking into account that our patients already received maximum guideline-based therapy. In addition, we were able to demonstrate a decline in left ventricular diameter, indicating a possible reverse remodelling effect. The present study does not allow any conclusions regarding long-term prognosis and the influence of ASV, however, an inverse relationship between EF and mortality has been documented in $\mathrm{CHF}$ patients and mid-term $\mathrm{LV}$ reverse remodelling might be a predictor of improved long-term outcome [28-30].

Cardiopulmonary function improved in ASV patients as demonstrated by workload, $\mathrm{VO}_{2}$ - $\mathrm{AT}$, and $\mathrm{VO}_{2}$-peak, as well as predicted $\mathrm{VO}_{2}$-peak during $\mathrm{CPX}$ testing. These changes are comparable to those reported previously [22]. Compared to Schädlich et al., 6-min walking distance in our study was considerably lower at baseline. This might be one reason while improvement was significant, but lower than that reported by Schädlich [21]. Nonetheless, walking distance in controls remained unchanged.

In a recently published study, we demonstrated a beneficial effect of ASV and Cheyne-Stokes respiration in patients with heart failure and normal ejection fraction (HFNEF) [31]. In close agreement with the present study in heart failure patients with reduced ejection fraction, we documented a long-lasting and significant improvement in symptoms, sleep-disordered breathing parameters, echocardiographic parameters of diastolic function, and cardiopulmonary exercise testing parameters.
Focus of the present study was the investigation of respiratory stability. For the first time we demonstrated a substantial improvement in several of these parameters by ASV treatment. Comparing the effects of oxygen and CPAP on respiratory stability, Arzt et al. [32] showed a beneficial effect of CPAP on $\mathrm{VE} / \mathrm{VCO}_{2}$-slope in $\mathrm{CHF}$ patients with nocturnal CSR. In their study, no effects of either oxygen or CPAP on resting $\mathrm{pCO}_{2}$ were seen. This may be explained by the short follow-up period of 12 weeks and the relatively small number of patients investigated (CPAP: $n=14$; oxygen: $n=10$ ). In contrast, the present results confirm our previous findings and results of Pepperell et al. [18, 22] that ASV was able to effectively control nocturnal CSR resulting in a reduction of daytime hyperventilation with a rise of daytime resting $\mathrm{pCO}_{2}$. It also reveals a possible underlying pathophysiological mechanism that sensitivity of central $\mathrm{CO}_{2}$ receptors was changed. A reduced $\mathrm{VE} / \mathrm{VCO}_{2}$-slope and a lower amount of EOV or hyperventilation $\left(\mathrm{pCO}_{2}\right)$ at rest are a result of improved ventilatory control (HCVR).

We did not investigate cycle lengths of CSR. Especially parameters like circulatory delay, but also left ventricular filling pressures improved parallel to cardiac function and therefore may have additional beneficial and stabilizing effects on respiration [8, 33].

We cannot distinguish whether documented beneficial changes in parameters of respiratory instability occurred because respiratory control was directly modified by nocturnal ASV therapy or if improved cardiac function with assumed lower filling pressures led to less stimulation of vagal irritant receptors and normalisation of augmented $\mathrm{CO}_{2}$ receptor sensitivity. One common pathway to favourably modulate $\mathrm{CO}_{2}$ receptor sensitivity is to decrease sympathetic nervous drive. As CSA and CHF lead to increased sympathetic activity, they might augment $\mathrm{CO}_{2}$ receptor sensitivity. In contrast, effective heart failure treatment itself, as well as effective CSR therapy can decrease sympathetic nervous activity and thus might normalise $\mathrm{CO}_{2}$ receptor sensitivity [18, 34-36].

However, normalisation in $\mathrm{CO}_{2}$ receptor sensitivity seems to be the key to improve all other parameters of respiratory stability.

\section{Limitations}

This study was not initiated as a randomized controlled trial. Patients of our control group rejected ASV treatment or were less compliant to ASV therapy than those in the verum group. Therefore, one might speculate that these patients were less compliant regarding standard heart failure treatment, however, most of these patients belong to our outpatient facility and most of them have pacemakers, ICD, or CRT devices which need to be interrogated in 3- or 
6-month intervals, they were seen routinely and medication did not change over time. Another limitation is the lacking routine and standardised polygraphic or polysomnographic follow-up in our control group. However, according to a recent study by Pinna et al. [37], heart failure patients experience persistent clinically significant nocturnal breathing disorders over long periods of time and rarely do they show a steady increase or decrease over time.

\section{Conclusion}

In heart failure patients with nocturnal CSR, ASV might be able to improve parameters of SDB, cardiac function, and respiratory stability. These parameters are of proven prognostic impact, however, improvement of these surrogate parameters leads to an improvement in patient's prognosis must be determined. Randomised controlled studies are underway to investigate these effects.

\section{References}

1. Oldenburg O, Lamp B, Faber L, Teschler H, Horstkotte D, Töpfer V (2007) Sleep disordered breathing in patients with symptomatic heart failure. Eur J Heart Fail 9:251-257

2. Schulz R, Blau A, Börgel J, Duchna HW, Fietze I, Loper I, Prenzel R, Schädlich S, Schmitt J, Tasci S, Andreas S (2007) Sleep apnoea in heart failure. Eur Respir J 29:1201-1205

3. Javaheri S, Shukla R, Zeigler H, Wexler L (2007) Central sleep apnea, right ventricular dysfunction, and low diastolic blood pressure are predictors of mortality in systolic heart failure. J Am Coll Cardiol 49:2028-2034

4. Yumino D, Wang H, Floras JS, Newton GE, Mak S, Ruttanaumpawan P, Parker JD, Bradley TD (2009) Relationship between sleep apnoea and mortality in patients with ischaemic heart failure. Heart 95:819-824

5. Wang H, Parker JD, Newton GE, Floras JS, Mak S, Chiu KL, Ruttanaumpawan P, Tomlinson G, Bradley TD (2007) Influence of obstructive sleep apnea on mortality in patients with heart failure. J Am Coll Cardiol 49:1625-1631

6. Oldenburg O, Bitter T, Wiemer M, Langer C, Horstkotte D, Piper C (2009) Pulmonary capillary wedge pressure and pulmonary artery pressure in heart failure patients with sleep-disordered breathing. Sleep Med 10:726-730

7. Solin P, Roebuck T, Swieca J, Walters E, Naughton M (1998) Effects of cardiac dysfunction on non-hypercapnic central sleep apnea. Chest 113:104-110

8. Solin P, Bergin P, Richardson M, Kaye D, Walters E, Naughton M (1999) Influence of pulmonary capillary wedge pressure on central apnea in heart failure. Circulation 99:1574-1579

9. Ryan C, Floras J, Logan A, Kimoff RJ, Series F, Morrison D, Fergusion KA, Belenkie I, Pfeifer M, Fleetham J, Hanly PJ, Smilovitch M, Arzt M, Bradley TD (2010) Shift in sleep apnoea type in heart failure patients in the CANPAP trial. Eur Respir J 35:592-597

10. Andreas S, Morguet A, Werner G, Kreuzer H (1996) Ventilatory response to exercise and to carbon dioxide in patients with heart failure. Eur Heart J 17:750-755
11. Javaheri S (1999) A mechanism of central sleep apnea in patients with heart failure. N Engl J Med 341:949-954

12. Solin P, Roebuck T, Johns D, Walters E, Naughton M (2000) Peripheral and central ventilatory responses in central sleep apnea with and without congestive heart failure. Am J Respir Crit Care Med 162:2194-2200

13. Wilcox I, McNamara S, Dodd M, Sullivan C (1998) Ventilatory control in patients with sleep apnoea and left ventricular dysfunction: comparison of obstructive and central sleep apnoea. Eur Respir J 11:7-13

14. Xie A, Rutherford R, Rankin F, Wong B, Bradley TD (1995) Hypocapnia and increased ventilatory responsiveness in patients with idiopathic central sleep apnea. Am J Respir Crit Care Med 152:1950-1955

15. Corrá U, Giordano A, Bosimini E, Mezzani A, Piepoli M, Coats AJS, Giannuzzi P (2002) Oscillatory ventilation during exercise in patients with chronic heart failure. Chest 121:1572-1580

16. Teschler H, Döhring J, Wang Y-M, Berthon-Jones M (2001) Adaptive pressure support servo-ventilation. A novel treatment for Cheyne-Stokes respiration in heart failure. Am J Respir Crit Care Med 164:614-619

17. Allam JS, Olson EJ, Gay PC, Morgenthaler TI (2007) Efficacy of adaptive servoventilation in treatment of complex and central sleep apnea syndromes. Chest 132:1839-1846

18. Pepperell J, Maskell N, Jones D, Langfort-Wiley BA, Crosthwaite N, Stradling JR, Davies RJO (2003) A randomized controlled trial of adaptive ventilation for Cheyne-Stokes breathing in heart failure. Am J Respir Crit Care Med 168:1109-1114

19. Töpfer V, El-Sebai M, Wessendorf T, Moraidis I, Teschler H (2004) Adaptive servoventilation bei chronischer Herzinsuffizienz: Wirkung auf Cheyne-Stokes-Atmung und Lebensqualität. Pneumologie 58:28-32

20. Philippe C, Stoica-Herman M, Drouot X, Raffestin B, Escourrou P, Hittinger L, Michel PL, Rouault S, d'Ortho MP (2006) Compliance with and efficacy of adaptive servo-ventilation (ASV) versus continuous positive airway pressure (CPAP) in the treatment of Cheyne-Stokes respiration in heart failure over a six month period. Heart 92:337-342

21. Schädlich S, Königs I, Kalbitz F, Blankenburg T, Busse H, Schütte W (2004) Kardiale Leistungsfähigkeit bei Patienten mit Cheyne-Stokes-Atmung infolge Herzinsuffizienz während langfristiger Beatmungstherapie mittels adaptiver Servoventilation (AutoSet CS ${ }^{\circledR}$ ). Z Kardiol 93:454-462

22. Oldenburg O, Schmidt A, Lamp B, Bitter T, Muntean B, Langer C, Horstkotte D (2008) Adaptive servoventilation improves cardiac function in patients with chronic heart failure and CheyneStokes respiration. Eur J Heart Fail 10:581-586

23. Zhang X, Yin K, Li X, Jia E, Su M (2006) Efficacy of adaptive servoventilation in patients with congestive heart failure and Cheyne-Stokes respiration. Chin Med J 119:622-627

24. Enright PL (2003) The six-minute walk test. Respir Care 48:783-785

25. Read D (1966) A clinical method for assessing the ventilatory response to carbon dioxide. Australas Ann Med 16:20-32

26. Hole T, Froland G, Gullestad L, Offstad J, Skjaerpe T (2004) Metoprolol CR/XL improves systolic and diastolic left ventricular function in patients with chronic heart failure. Echocardiography 21:215-223

27. Pires LA, Abraham WT, Young JB, Johnson KM (2006) Clinical predictors and timing of New York Heart Association class improvement with cardiac resynchronization therapy in patients with advanced chronic heart failure: results from the Multicenter InSync Randomized Clinical Evaluation (MIRACLE) and Multicenter InSync ICD Randomized Clinical Evaluation (MIRACLE-ICD) trials. Am Heart J 151:837-843 
28. Gustafsson F, Torp-Pedersen C, Brendorp B, Seilbaek M, Burchardt H, Kober L (2003) Long-term survival in patients hospitalized with congestive heart failure: relation to preserved and reduced left ventricular systolic function. Eur Heart J 24:863-870

29. Solomon SD, Anavekar N, Skali H, McMurray JJ, Swedberg K, Yusuf S, Granger CB, Michelson EL, Wang D, Pocock S, Pfeffer MA (2005) Influence of ejection fraction on cardiovascular outcomes in a broad spectrum of heart failure patients. Circulation 112:3738-3744

30. Ypenburg C, van Bommel RJ, Borleffs CJ, Bleeker GB, Boersma E, Schalij MJ, Bax JJ (2009) Long-term prognosis after cardiac resynchronization therapy is related to the extent of left ventricular reverse remodeling at midterm follow-up. J Am Coll Cardiol 53:483-490

31. Bitter T, Westerheide N, Faber L, Hering D, Prinz C, Langer C, Horstkotte D, Oldenburg O (2010) Adaptive servoventilation in diastolic heart failure and Cheyne-Stokes respiration. Eur Respir J 36:385-392

32. Arzt M, Schulz M, Wensel R, Montalvan S, Blumberg FC, Riegger G, Pfeifer M (2005) Nocturnal continuous positive airway pressure improves ventilatory efficiency during exercise in patients with chronic heart failure. Chest 127:794-802
33. Wedewardt J, Bitter T, Prinz C, Faber L, Horstkotte D, Oldenburg O (2010) Cheyne-Stokes respiration in heart failure: cycle length is dependent on left ventricular ejection fraction. Sleep Med 11:137-142

34. Floras JS (2009) Sympathetic nervous system activation in human heart failure: clinical implications of an updated model. J Am Coll Cardiol 54:375-385

35. Kaye D, Mansfield D, Aggarwal A, Naughton M, Esler M (2001) Acute effects of continuous positive airway pressure on cardiac sympathetic tone in congestive heart failure. Circulation 103:2336-2338

36. Naughton M, Benard D, Liu P, Rutherford R, Rankin F, Bradley TD (1995) Effects of nasal CPAP on sympathetic activity in patients with heart failure and central sleep apnea. Am J Respir Crit Care Med 152:473-479

37. Pinna GD, Maestri R, Mortara A, Johnson P, Andrews D, Ponikowski P, Witkowski T, La Rovere MT, Sleight P (2010) Longterm time-course of nocturnal breathing disorders in heart failure patients. Eur Respir J 35:361-367 